\title{
La familia Berman-Rodríguez. Exploración de los problemas, límites y potencialidades de un archivo personal/familiar
}

\author{
Claudia Freidenraij* y Ludmila Scheinkman**
}

\begin{abstract}
Hace varios años que cuatro cajas de cartón bordó habitan una esquina de mi casa. 'Llegaron una tarde, en el baúl de mi auto. "Lucas te manda esto", dijo mi marido cuando las apoyó en el suelo. Lucas Pedro, su amigo de la infancia, estaba atravesando un duelo por partida doble y en ese momento oscuro su generosidad se impuso: rescató esas cajas que de otro modo probablemente hubieran terminado en la basura, y me nombró su albacea. Cuando hurgué en su contenido supe de inmediato que tenían un valor incalculable para mis líneas de trabajo en torno a la historia de las infancias y familias en Argentina. Pero, abrumada por el tamaño y peso del archivo, cerré las cajas. Desde entonces convivimos en mi estudio. Cada tanto su silencio me increpa. Hace un tiempo le propuse a Ludmila sumergirnos en la historia familiar que albergaban para pensar el valor de los archivos personales/familiares. Esta convocatoria fue la excusa para poner esa reflexión por escrito. El resultado es lo que sigue.
\end{abstract}

\section{Lxs Berman-Rodríguez}

Lxs Berman-Rodríguez fueron "gente común": integrantes de una clase media porteña, relativamente blanca y educada, con aspiraciones profesionales y familiares posiblemente similares a las de muchas otras familias de la Ciudad de Buenos Aires. Durante décadas, tanto los Berman como los Rodríguez, antes y después de emparentarse, fueron archivando el patrimonio familiar: atesoraron pequeños recortes y documentos oficiales, mechones de pelo de hijxs y nietxs intercalados con carnets de afiliación a clubes y sindicatos, boletines escolares, correspondencia íntima y administrativa y una enorme cantidad de fotografías tomadas a lo largo del siglo XX. Una colección de recuerdos y memorabilia

* Ravignani, FfyL-UBA/CONICET

** IIEGE, FfyL-UBA/CONICET

1 Agradecemos a Lucas Berman y Carmen Rodríguez por su generosidad al compartirnos su historia y su archivo familiar. familiar cuyo orden y sentido a simple vista nos elude más allá de su evidente significación emotiva y/o legal para quienes la agruparon, mezclada y tamizada sin cronología aparente ni criterio de clasificación alguno. Involucrando a mujeres de diferentes generaciones, esta labor de conservación de la memoria familiar se extiende a lo largo de las cajas, y su lectura se prolonga por días, lejos aún de cualquier catalogación o fichaje.

¿Para qué sirven los archivos personales de la "gente minúscuLa"? ¿Qué se puede estudiar a partir de ellos? ¿Cómo ficharlos, conservarlos, ordenarlos? ¿Cómo situar la disparidad de elementos que los componen, registrando la intervención de distintas personas a lo largo de generaciones?

En este archivo abundan los indicios. Diversas pistas nos invitan a indagar la cultura material, la historia de la vida privada, de las emociones, los roles de género, la maternidad y los mandatos familiares, la infancia, o los anhelos de escolarización y profesionalización volcados en hijxs que cumplen con creces la expectativa familiar. En el relato del ascenso social de estas familias, también aparecen el dictum de la domesticidad y la vida cotidiana, los hitos de pasaje en el curso de vida y la historia personal, así como los afectos de abuelxs, madres y padres por lxs vástagos que crecen y cuyos rastros de crecimiento van volcándose en forma del registro de los aumentos de peso del bebé, diplomas de egreso, fotos de comuniones, cumpleaños, casamientos, viajes y vacaciones familiares, y nos permiten indagar en la "vida privada" de esa "gris clase media" que ha cobrado cada vez más significación en los estudios históricos en los últimos años.

Siguiendo estas pistas, el objetivo de este trabajo es una primera aproximación al archivo personal de la familia Berman-Rodríguez [ca. 1897-2010] -una familia de clase media porteña-, para reflexionar en torno a los límites, potencialidades y vías que se abren a partir de la exploración de fondos de "gente común". Esperamos que esta reflexión en torno a los archivos personales de personajes y familias anónimas sea una ocasión para pensar 
posibles líneas de indagación, como así también un alegato en torno a la necesidad de incentivar el acopio y la conservación de los archivos familiares en instituciones especializadas a tal fin.

\section{Los gestos del guardar}

A primera vista no hay orden aparente. Las cajas guardan objetos disímiles. Recortes de prensa, una muñeca, cédulas de identidad, álbumes de recuerdos, boletines escolares, permisos de conducir, invitaciones a bodas, bautizos y cumpleaños, listas de regalos recibidos en distintas ocasiones, certificados de nacimientos y defunciones, algunos libros y revistas especializadas en arquitectura, cartas, notitas y dibujos infantiles, correspondencia entre amigxs y familiares, pasaportes, boletines de La empresa Gas del Estado, carnets sindicales y deportivos, actas de compra de terrenos y certificados de transferencia de automóviles, programas de teatro y de exposiciones, diplomas de violín, libretas de ahorro y universitarias, un sinfín de fotografías en todos los tonos y tamaños y hasta una lata de bootpolish con un cepillo y una ballerina, la hebilla de un cinturón y una billetera sin estrenar. Y sin embargo, aquello que las personas conservan de su propia historia, es apenas una parte ínfima de los vestigios de nuestro paso por la vida. ${ }^{2}$

Una multiplicidad de registros conviven den-

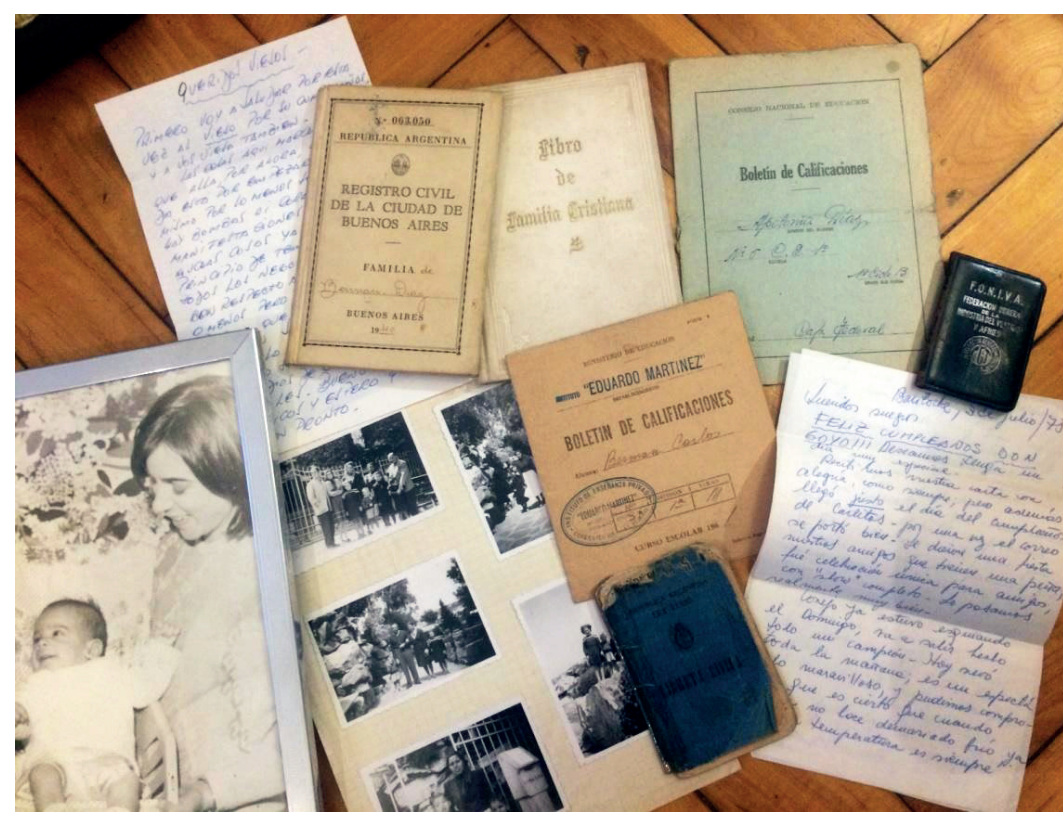
tro de estas cuatro cajas: documentos administrativos, de valor sentimental, colecciones, memorabilia, recuerdos, recortes, una selección de libros vinculados a la profesión, objetos varios (Imagen 1). Los documentos de identidad se superponen con las cartas de amor y de ruptura; la libreta cívica acompaña a las fotos de viajes y paseos; las postales del mundo recolectadas a lo largo de una vida, ordenadas escrupulosamente en un álbum ad hoc, conviven con necrológicas de algunos miembros de la familia publicadas en distintos medios. El valor afectivo de muchos de estos objetos se recorta contra el fondo más pálido de ciertos papeles administrativos, que dan cuenta de la vida de quienes fueran sus portadores. ${ }^{3}$ Philippe Artières señala que los docu-

2 Georges Perec, Especies de espacios, Barcelona, Montesinos, 2001 [1974].

3 Conviene, sin embargo, prevenirnos: un documento estándar como el carnet de socio del ACA nos habla de una familia que se desplaza asiduamente por el territorio, así como las fotos de vacaciones en Piriápolis, Mar del Plata o el Tigre. En el mismo sentido, el carnet de socio de GEBA no es apenas un indicio de la actividad deportiva de su titular, sino que constituye una huella más de un círculo de relaciones y de prácticas de sociabilidad que continúan hasta la actualidad a través de generaciones. mentos que componen los archivos personales se pueden ubicar sobre una curva que va desde lo colectivo a lo personal. En uno de sus extremos, sostiene, "existe un archivo que está enteramente compuesto por escritos de otros, o, por lo menos, muy expuesto a la mirada", tales como los documentos de identidad o los álbumes de fotos, cuya función es "de ceremonia e inscripción social". En el otro extremo, en cambio, encontramos "escenas que amplían la escritura para sí, en especial cuando la línea biográfica se quiebra o cuando los compromisos existenciales se bifurcan", en el caso por ejemplo de separaciones o divorcios. Entre esos extremos, por último, "encontramos toda una gama de escrituras en el escenario de las instituciones".4 
mera y posible clasificación. ${ }^{5}$ Los más recientes son los papeles de Lucas. Recuerdos escolares, cartitas infantiles y de juventud, fotos de viajes de adolescencia y sus primeros años de adultez (con amigos, su primera novia o solo en Europa), y también papeles y libros que remiten a su pasaje por la universidad como estudiante de arquitectura, y a sus inicios como arquitecto especializado en conservación patrimonial. ¿Fueron estos papeles guardados por Lucas? ¿O quedaron en la casa materna y fueron luego archivados por su madre?

Tras los de Lucas, un segundo cuerpo de papeles se vislumbra: los de la familia Berman. Estos incluyen documentos del padre de Lucas, fotógrafo y viajero — su residencia en Bariloche junto a la madre de Lucas, su separación y mudanza a Brasil, su pareja en Peruíbe, papeles relativos a su divorcio (vía México, en los años 70, y tras la ley de divorcio en Argentina en los años 90), su separación y luego muerte-, y los documentos de sus abuelos paternos, Isaac y Apolonia Díaz. De ellos sabemos poco. Se casaron en 1940, ella con 23 años, él con 32, bajo el rito católico. Ella era oriunda de Santiago del Estero, de padre desconocido —así figura en actas—, y afición católica — juntaba estampitas—. Su origen social humilde y trabajador se desprende de su trabajo de costurera -atestiguado por su carnet de socia del Sindicato Obrero de la Industria del vestido y afines-; pero también de su libreta de calificaciones cumplimentando la escuela primaria en 1964, con casi 50 años. Su letra temblorosa pero llena de orgullo, felicitando al nieto al recibirse de arquitecto, permite suponer un aprendizaje tardío de la escritura pero también una historia de ascenso social. De Isaac sabemos poco más allá de su afición a los autos — posa junto a ellos en muchas fotos, estaba afiliado al Automóvil Club Argentino-. La pareja aparece danzante y feliz en fotos de viajes por el país — ¿una luna de miel o tal vez unas vacaciones en Mar del Plata en los años 40?-, y en retratos familiares con los hijos. Con todo, los papeles de los Berman son pocos y no se remontan muy lejos en el tiempo.

La que domina el corpus del archivo es sin dudas la familia Rodríguez. Una figura se destaca en el elenco familiar. Aida Susana, la madre de Lucas, reunió y recopiló muchos de esos objetos, algunos de los cuales clasificó y ordenó: un álbum de postales, un álbum genealógico que recopila su historia familiar. Hizo un trabajo de búsqueda de esas huellas - muchas fotos y documentos indican quién los legó o le permitió fotocopiarlos-, y reprodujo actas de nacimiento, fotografías y notas periodísticas. Se esmeró al dedicarse a la figura de su padre, de quien reunió una considerable cantidad de documentos que lo muestran a lo largo de su vida en múltiples facetas: su vida escolar y universitaria, la

5 Patricia Funes sostiene que una de las claves de lectura de los archivos personales está en la forma en que están ordenados y seleccionados los documentos. Patricia Funes, "A veces enciendo la luz para no ver: memoria, archivo personal y espacio biográfico", en VIII Jornadas de Sociología de la UNLP, Ensenada, UNLP, 2014, disponible en http://www. memoria.fahce.unlp.edu.ar/trab_eventos/ev.4471/ev.4471.pdf. boda con quien sería su única esposa y madre de sus hijas, Aída Carmen (por contraste, significativamente ausente en la reconstrucción), la llegada de su primogénita Susanita, su trayectoria profesional en empresas de gas. A Pedro Francisco Rodríguez el peronismo lo encontró a involucrado en la obra más significativa del área, el gasoducto Comodoro Rivadavia. ${ }^{6}$ La fiesta de su $50^{\circ}$ aniversario, que incluye la lista de obsequios recibidos, nos lo muestra como un profesional de clase media acomodada con una reconocida trayectoria profesional, cuyas hijas asisten a escuelas inglesas, viajando a Europa con su esposa y recibiendo regalos costosos. Un relato del ascenso social, de la vida exitosa del hijo de un comerciante de indumentaria masculina.

Sin embargo, estos relatos hay que encontrarlos. No surgen a simple vista. El primer gesto de Aida Susana, que pareciera ser el de una acumulación sin orden ni concierto, es en realidad un recorte, una mirada específica. ${ }^{7}$ Es necesario interrogarnos por el sentido y significado de ese orden como una forma posible de pensar lo que hay detrás de la construcción de este archivo. Uno de los objetivos posibles, entonces, frente a un archivo personal/familiar, es descifrar los posibles criterios detrás de la conservación, tarea que se hace difícil sin las palabras de las personas involucradas. A modo de ejercicio, nos propusimos realizar esta primera aproximación al archivo de los Berman-Rodríguez sin la ayuda y guía de su propietario. Pero, ¿cuán valioso sería, para mejor entender aquello que tenemos entre manos, la voz de quien decide que esas cajas pueden ser valiosas para las y los historiadores? ¿Cuánto ganaríamos si cada donación, o derecho de usufructo, viniera acompañado de una entrevista en profundidad, que fuese hilvanando cada artefacto del archivo, dando sentido a esas piezas aparentemente sueltas, reponiendo los silencios del papel y aportando otros relatos que enriquezcan aún más el fondo documental?.

\section{Líneas de fuga}

La interrogación, sin embargo, trasciende de la materialidad del archivo hacia sus posibles usos para la investigación histórica. ¿Cuál es la importancia de conservar los archivos personales/familiares de la "gente común"? ¿En qué medida pueden emplearse para, más allá de la anécdota y el detalle particular, indagar en dimensiones de lo social? Los puntos de fuga posibles son

6 Con el golpe de 1955 Pedro Francisco termina preso unos meses, para luego salir exonerado. Significativamente, ningún papel de los muchos que compone este fondo da cuenta de esa experiencia, repuesta oralmente por Carmen Rodríguez, tía materna de Lucas.

7 "No archivamos nuestras vidas, no ponemos nuestras vidas en conserva de cualquier manera; no guardamos todas las manzanas de nuestra cesta personal; hacemos un acuerdo con la realidad, manipulamos la existencia: omitimos, rasuramos, rasguñamos, subrayamos, destacamos ciertos pasajes". Philippe Artières, "Arquivar a própria vida", en Estudos Historicos, $n^{\circ} 21,1998$, p. 11. 
múltiples y variados. Indagar en la vida de "los actores anónimos de lo social" nos permite sin dudas auscultar dimensiones de la reproducción social (biológica, generacional, pero también familiar y social/vincular, de la reproducción de clase, de los roles sexo-genéricos), pero también bucear en sus transformaciones, su historicidad y su variación en el tiempo. ${ }^{8}$

El primer contacto con este archivo fue el de un estallido en las manos: podía hablarnos de muchas cosas, con distinta intensidad y desde diferentes lugares, y ciertamente los diálogos posibles eran muchos. Dependiendo de las preguntas y el ajuste de la lupa, estos papeles podrían ser útiles para quienes trabajan sociabilidades y problemas vinculados a las trayectorias profesionales. También podrían colaborar con quienes están pensando la historia del ocio y el turismo o con quienes indagan las manifestaciones cotidianas de la religiosidad. En igual sentido, mucho del material sobre arquitectura y conservación patrimonial podría ser de interés para quienes reconstruyen ciertas formas de pensar el espacio, las ciudades y su patrimonio arquitectónico. No menos valioso es su interés para quienes estudian las redes y procesos migratorios.

Sin embargo, de las muchas aristas posibles que un archivo como éste despierta, nos interesa profundizar en tres de ellas, como una forma de argumentar acerca de sus potencialidades para la investigación histórica, y por lo tanto de la necesidad de su conservación: (a) la historia de las clases medias y del ascenso social; (b) la historia de las infancias y familias, en consonancia con los estudios de la historia de la afectividad y (c) una historia material de la felicidad infantil.

\section{(a) La historia de las clases medias y del ascenso social}

Los relatos del ascenso social, ligados a la emergencia de las clases medias como actores sociales y políticos a partir de las décadas del '20 y '30, pero cobrando fuerzas en los años '40, suelen presentarse muchas veces como historias de ascenso individual, del hombre que emprende y "se hace a sí mismo". ¿Fueron las carreras al ascenso aventuras puramente masculinas e individuales? Este archivo nos invita a pensar en los linajes y en la "aventura del ascenso" como un proceso tanto individual como sustentado sobre lazos familiares. Y también en la construcción femenina del relato del ascenso, a través de la recolección, organización y acopio de los logros masculinos en la arena laboral. Siguiendo la historia de varias generaciones de la familia Rodríguez a través del siglo $\mathrm{XX}$, podemos observar la reproducción familiar y el afianzamiento de una posición de clase media. ${ }^{9} \mathrm{El}$

Philippe Artières, "S'archiver (Archivarse)", op. cit., p. 39.

9 Los estudios sobre las clases medias se han multiplicado en los últimos años. Ver, entre otros: Carlos Altamirano, "La pequeña burguesía, una álbum familiar, posiblemente iniciado por Aída Carmen y luego organizado por su hija Susana, permite seguir esta trayectoria. Éste empieza con el acta de nacimiento de Valeriana Fernández Rodríguez (la abuela paterna de Susana y bisabuela de Lucas) y su marido don Emilio Rodríguez. Migrantes italianos, los Rodríguez llegaron a Argentina a comienzos del siglo XX, aunque las primeras fotos del acervo son de fines del siglo XIX. Seguramente arribaron con un pequeño capital, pues un recorte de periódico de 1910 nos informa sobre su comercio, la sombrerería y camisería Los Maragatos, ubicada en Cangallo 1100 esquina Cerrito.

Tal vez haya sido la bisabuela, Valeriana Fernández Rodríguez, quien comenzara la recolección. Los logros de su hijo Pedro son asentados desde pequeño. Junto a fotos familiares, el boletín escolar de Pedro nos indica el camino de los éxitos académicos y profesionales, su paso por el Colegio Nacional Juan Martín de Pueyrredón y sus diplomas de violín en su paso por el Conservatorio. También nos habla de sus espacios de sociabilidad: sus fotos en el club Gimnasia y Esgrima de Buenos Aires (GEBA) o en la Confitería Ideal con sus compañeros de curso del Colegio Nacional, jóvenes con sombreros y trajecitos. Otra nota de periódico nos cuenta que Pedro se graduó de Ingeniero Civil en la Universidad de Buenos Aires (UBA) con una beca de la Compañía Argentina de Electricidad que le permitió estudiar inglés. Ya de adulto, vemos la invitación a su casamiento con Aida Carmen Canzonieri en 1943, acompañada por fotos del evento y de su luna de miel en Mar del Plata. Luego las fotos de su hija mayor, Aida Susana, y de Carmen, la menor, en distintos escenarios: unas vacaciones en Piriápolis, viajes al Tigre, Mar del Plata y Miramar, su primera comunión, tarjetas de comunión y bautizos de otras personas. El recorrido laboral de Pedro continúa intercalado con las vicisitudes familiares: notas de periódicos lo muestran inaugurando servicios de gas, junto con fotos laborales en YPF Gas, la Compañía Primitiva de Gas y posteriormente Gas del Estado (Imagen 2). Otros objetos del archivo colaboran a esta historia de la trayectoria profesional de Pedro. Un ejemplar de Quien es quien en la Argentina de 1968, con una entrada sobre Pedro Francisco Rodríguez, administrador general de Gas del Estado entre 1952-55, el libro El gasoducto Comodoro Rivadavia-Buenos Aires, de 1948, que incluye un texto suyo; un ejemplar de la revista Al calor de nuestra llama, publicada por

clase en el purgatorio", en Prismas, n 1, 1997, pp. 105-123; Ezequiel Adamovsky, Historia de la clase media argentina: apogeo y decadencia de una ilusión, 1919-2003, Buenos Aires: Planeta, 2009; Sergio Visacovsky y Enrique Garguin, Moralidades, economías e identidades de clase media (Buenos Aires, Antropofagia, 2009); Isabella Cosse, "Mafalda: Middle Class, Everyday Life and Politics in Buenos Aires, 1964-1973", en Hispanic American Historical Review, vol. 1, n 94, enero de 2014, pp. 35-75; Mafalda: Historia social y política, Buenos Aires, Fondo de Cultura Económica, 2014; Valeria Manzano, "'Y, ahora, entre gente de clase media como uno...'.Culturas juveniles, drogas y política en la Argentina, 1960-1980", en Contemporánea. Historia y problemas del siglo XX,$n^{\circ}$ 5 (2014), pp. 85-104; Graciela Queirolo, Mujeres en las oficinas. Trabajo, género y clase en el sector administrativo (Buenos Aires, 1910 1950), Buenos Aires, Biblos, 2018 
Gas del Estado en 1970, con una nota firmada por él; recortes varios de periódicos.

\section{Imagen 2. Pedro Francisco Rodríguez} inaugurando obras públicas de gas. Archivo familiar Berman-Rodríguez, $s / f$.

Aunque el matrimonio no tuvo hijos varones, tanto Aída Susana como su hermana María del Carmen fueron al colegio inglés Highlands en $\mathrm{Vi}$ cente López — se dedicarían luego a la enseñanza del idioma-, y apren-

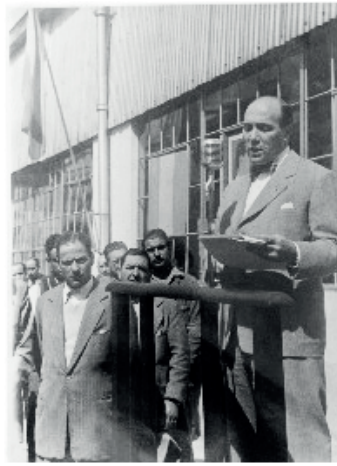
dieron piano y danzas tradicionales españolas. Algunos hitos en el álbum de Susana marcan la pertenencia y los rituales de esta clase media. Uno de ellos es la fiesta de 50 años del padre, celebrada el 23 de septiembre de 1964, acompañada de fotos y una extensa lista de regalos para Pedro que nos permite pensar los consumos y estilos de vida de las clases medias (Imagen 3$)^{10}$

Otro ritual de pertenencia es el viaje de sus padres a Europa en 1966, o la fiesta de 15 años de Susana. Hacia el final del álbum encontramos fotos de Susana embarazada, las primeras fotos de su hijo Lucas y fotos del casamiento de su hermana. Sabremos por los datos de los Berman que Carlos Alberto, el padre de Lucas, ya estaba casado y no podía por lo tanto formalizar la unión. Que Susana y Carlos formaran una pareja y decidieran tener un hijo sin haber pasado antes por el registro civil, contraviniendo el modelo de matrimonio católico indisoluble "para toda la vida", encarnado por los padres de ambos, puede pensarse en el marco de esa "revolución discreta" que se desarrolla en las relaciones de pareja, sexualidad y familia en los años 60, estudiadas por Isabella Cosse. ${ }^{11}$ El álbum se cierra con la impresión de una nota de La Nación Online sobre la labor de su hijo, el arquitecto Lucas Pedro Berman, trabajando en la conservación patrimonial del Teatro Cervantes.

Aunque los papeles escolares y profesionales de Lucas no forman parte del álbum, podemos ver en el proceso de selección y recorte de Susana -tal vez heredado de su madre, Aída Carmen-, un claro énfasis en los vínculos familiares pero también en los logros profesionales, tanto de su abuelo como de su padre,

10 Esta incluye un cenicero de cristal, una billetera de cocodrilo, un llavero de oro con sus iniciales grabadas, unos gemelos de oro, un llavero de plata, una corbata y un juego de lapiceras Parker, entre otros costosos presentes. ¿Será uno de estos regalos la billetera sin estrenar encontrada dentro de la caja?

11 Isabella Cosse, Pareja, sexualidad y familia en los años sesenta. Una revolución discreta en Buenos Aires, Buenos Aires, Siglo XXI, 2010. Quizás los papeles de Carlos y Susana, esa nueva generación que vino a desafiar la normatividad doméstica, nos permitan adentrarnos un poco más en las transformaciones en los vínculos de pareja y la mutación de los códigos de conducta y los significados que establecían el contexto en que varones y mujeres se conocían, se unían y formaban una familia.

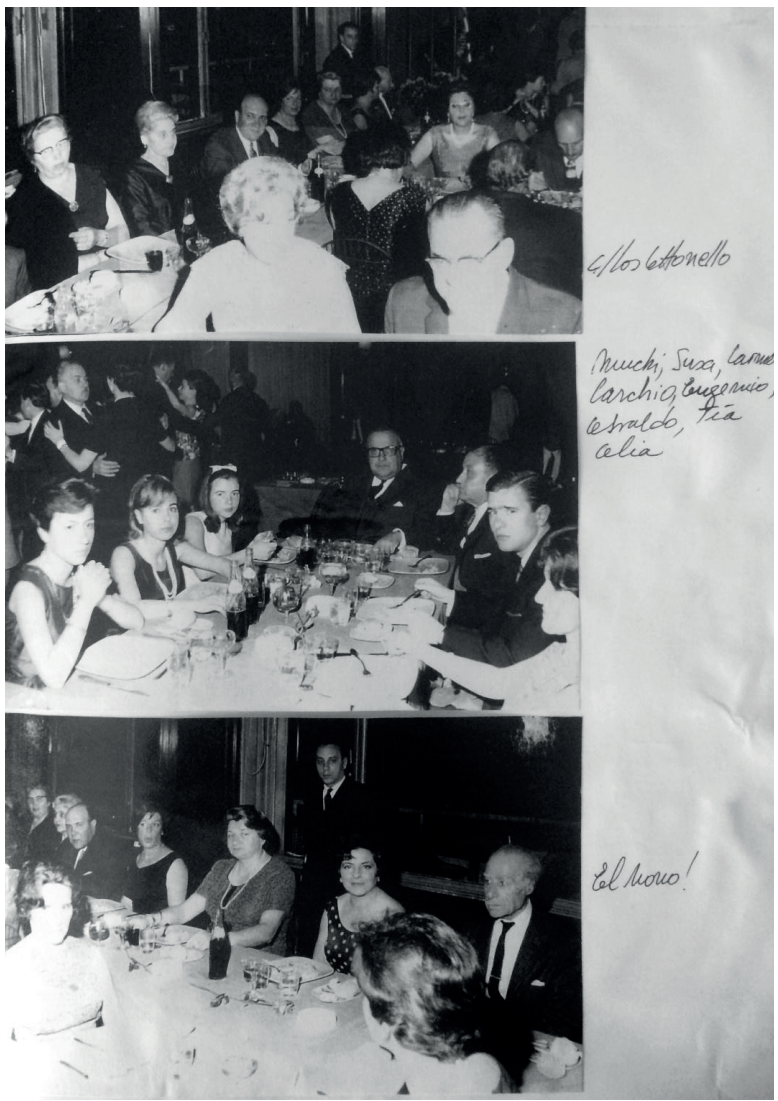

Imagen 3. Celebración del 50 aniversario del nacimiento de Pedro F. Rodríguez. 23/9/1964. Archivo familiar Berman-Rodríguez.

y luego su hijo. ${ }^{12}$ Se puede entrever así la construcción femenina del relato de ascenso social de una familia de clase media, tan consistente con la historia de "M’hijo el dotor". La posición económica de los bisabuelos habría permitido a Pedro asistir a la universidad y formarse como ingeniero, casarse convenientemente, enviar a sus hijas a un colegio privado, y Lucas, hijo de Susana y nieto de Pedro, continuó con la tradición familiar universitaria, graduándose de arquitecto.

El álbum de Susana nos cuenta del relato del ascenso social de esta familia, de la sensibilidad de las clases medias y la historia de la profesionalización —diversas fotografías muestran a Pedro F. entre sus pares del Colegio Nacional, de la Universidad y luego de Gas del Estado. También nos habla de ciertos consumos, festejos y rituales: el viaje a Europa, los regalos de aniversario, fiestas de 15 y casamientos, las clases de danza y, ya en los 60, el colegio privado de las hijas y el club GEBA, el mismo al que con-

12 Es llamativa la ausencia de sus propios papeles, de las huellas de su propia vida. Como si ella no fuese parte de ese linaje de hombres exitosos (su abuelo comerciante, su padre ingeniero, su hijo arquitecto), Susana se coloca a sí misma como mera guardiana de las credenciales de los varones de su vida. En ese relato, ella se desdibuja. Y sin embargo, la intención autobiográfica está ahí, en las prácticas de archivamiento de sí que trabajado Philippe Artières, "Arquivar a própria vida". 
currieron las tres generaciones. Estos fueron tanto espacios de socialización como de esparcimiento y vinculación social. Y nos invitan a reflexionar sobre la reproducción de clase, en la que cumplieron un papel tanto la carrera laboral masculina como las mujeres en el establecimiento de alianzas y la recolección y custodia de la historia del linaje, práctica que supone la elaboración de un relato de sí inscripto en la historia de los ancestros.

\section{(b) La historia de la infancia y la familia}

Mientras que los logros escolares y laborales masculinos pueblan el archivo, las mujeres aparecen en roles de afecto y sus trabajos son secundarios o se pierden y borronean en el entramado de los vínculos afectivos. Sin embargo, el altar doméstico que la alta cultura burguesa le ha reservado a las mujeres, funcionó para muchas de ellas como la plataforma desde la cual se volvieron guardianas de la historia de la familia. Archivar la vida propia y más aún la de la familia, se volvió un mandato social. ${ }^{13}$ Apolonia, la abuela de Lucas, parece haber sido con frecuencia la que ofició de fotógrafa de los muchachos de su vida, su marido Isaac (abuelo de Lucas) y sus hijos Carlos y Raúl (padre y tío de Lucas, respectivamente), a la vez que la persona que conservó esas fotos. ${ }^{14}$

La afectividad de los lazos familiares — particularmente femenina - aparece en el acto de custodiar la memorabilia del crecimiento de hijos e hijas - mechones de pelo amorosamente guardados en sobres minúsculos, el registro de los hitos de crecimiento así como la anotación de pesos y medidas de los vástagos a lo largo del tiempo-. Los festejos de cumpleaños, bautismos, graduaciones y otros eventos también encuentran su lugar en la construcción de la historia familiar. Postales de viajes, entradas de cine o teatro, cartas a familiares en el exterior, son otros soportes que sostienen el recuerdo del entramado de relaciones sociales y afectivas, así como de las prácticas de ocio, y nos hablan de las formas en que las familias vivieron su cotidianeidad. En este punto la variable del género es clave: las mujeres, a lo largo de generaciones, se alzaron en guardianas de un archivo familiar que se heredó, clasificó o reclasificó, reactualizando procesos de construcción de subjetividades personales e identidades familiares. La mayor intensidad de algunos vínculos, o los silencios, son significativos. En el álbum de Susana es

13 Philippe Artières, "Arquivar a própria vida", op. cit., pp. 9-34.

14 Las fotografías del clan Berman no tienen el grado de organización que presentan las de la familia Rodríguez. Frente a los álbumes tan cronológicamente organizados por Susana, el archivo de los Berman es mucho más caótico: cientos de fotos sueltas y sin referencia conviven con decenas de páginas de hojas de carpeta $\mathrm{N}^{\circ} 3$ cuadriculadas, también sueltas, sobre las que están pegadas algunas fotografías que parecen haber sido tomadas más o menos en serie, con algunas referencias de personas, lugares y fechas a mano. No parece ser la letra de Apolonia, sino tal vez la de alguno de sus hijos. diferencial la atención dedicada al padre y a la madre. También aparece desdibujado el vínculo con Carlos, el padre de su hijo, de quien se separó en los años '80, pero de quien Susana guardó las necrológicas aparecidas en varias publicaciones periódicas. Es que los archivos personales y/o familiares constituyen un material invaluable para percibir aquello que Perec llamó "lo infraordinario": "las experiencias cotidianas, las emociones minúsculas, las prácticas comunes y banales" que suelen escapar a la observación de lxs historiadorxs. ${ }^{15}$ En este marco, la historia de los sentimientos, los afectos y la vida cotidiana de las familias de clases medias es uno de los campos de estudio que más provecho puede sacar del trabajo sobre archivos personales y familiares. ${ }^{16}$

De gran evidencia es la relevancia de estos archivos para pensar la historia de la familia, la infancia, los ciclos vitales, así como la relación de varones y mujeres con el mercado de trabajo, la escolaridad y el mundo de lo "privado" o lo íntimo. Una primera constatación permite observar el contraste entre la enorme variedad de configuraciones familiares que muestran las familias Berman y Rodríguez y el modelo familiar cristalizado en los años '30 y ' 40 (que siguiendo a Cosse, estaba basado en la pauta nuclear, la reducción del número de hijos, la intensidad afectiva y la división de roles genéricos, donde las mujeres se afirmaban como amas de casa y los varones como proveedores). ${ }^{17}$ Es Llamativa la diversidad de los vínculos que se construyeron a lo largo del tiempo entre los miembros de ambas familias. Matrimonios de toda la vida y trayectorias afectivas más erráticas; niñxs nacidos dentro y fuera del matrimonio legal; niñxs criados por madres solteras; parejas que se casaron con un bebé en camino; otras que convivieron sin estar casadas, tuvieron hijos y más tarde se separaron. Hermanxs que estaban en los papeles pero cuya relación parecía no trascender lo compartido durante la infancia (para reaparecer luego, cuando se convirtieron en padres y tíos); primxs que se querían como hermanxs y alimentaron sus vínculos pese a vivir en distintos continentes.

Ahora bien, ¿en qué medida estos artefactos de la cultura material de la cotidianeidad y del universo de lo íntimo nos permiten aprehender mejor la historia de las relaciones familiares y los

15 Citado en Philippe Artières y Dominique Kalifa, "El historiador y los archivos personales: paso a paso", en Políticas de la memoria, $n^{\circ} 13$, 2012/13, p. 9

16 Algunas compilaciones recientes sobre la historia de la infancia y las familias: Isabella Cosse et al., Infancias: políticas y saberes en la Argentina y Brasil : siglos XIX y XXX, Buenos Aires, ANPCyT:UNGS Teseo, 2011; Sandra Carli, ed., La cuestión de la infancia: entre la escuela, la calle y el shopping, Buenos Aires, Paidós, 2006; Lucía Lionetti y Daniel Míguez, Las infancias en la historia argentina: intersecciones entre prácticas, discursos e instituciones, 1890-1960, Rosario, Prohistoria, 2010; Valeria Llobet, ed., Pensar la infancia desde América Latina: un estado de la cuestión, Buenos Aires, CLACSO, 2014; Carla Villalta, Infancia, justicia y derechos humanos, Bernal, Universidad Nacional de Quilmes, 2010; Paula Bontempo y Andrés Bisso, eds., Infancias y juventudes en el siglo XX, Buenos Aires, Teseo, 2018. Sobre la historia de las emociones ver María Bjerg, "Una genealogía de la historia de las emociones", en Quinto Sol, vol. 23, n 1, enero-abril, 2019.

17 Isabella Cosse, Pareja, sexualidad y familia en los años sesenta, op. cit.. 
vínculos afectivos de la clase media? Cartas de amor y de desamor nos hablan de la historia de las parejas, de los términos con que se construyeron las relaciones amorosas y de las palabras que se usaban para cortar esos lazos. Una carta especialmente descriptiva del desamor la recibió Carlos, el padre de Lucas, en 2005, cuando su tercera pareja decidió dejarlo estando él de viaje en Argentina. Lo explícito de la insatisfacción, de la aspiración a compartir con la pareja algo más que una rutina gris, o de la necesidad de experimentar otras sensaciones de mayor intensidad pueden resultarnos familiares y comprensibles a los lectores actuales de esa misiva. Pero nos resultaría extraño encontrarlas 50 años antes. Esa extrañación sugiere la posibilidad de historizar las relaciones afectivas. ${ }^{18}$ Sabemos que las parejas se han unido y separado en el pasado, mucho antes de la ley de matrimonio civil (1882) o de divorcio vincular (1989). Sin embargo, las razones que llevan a hombres y mujeres a embarcarse en relaciones de pareja o a cortar lazos cambian, mutan y se

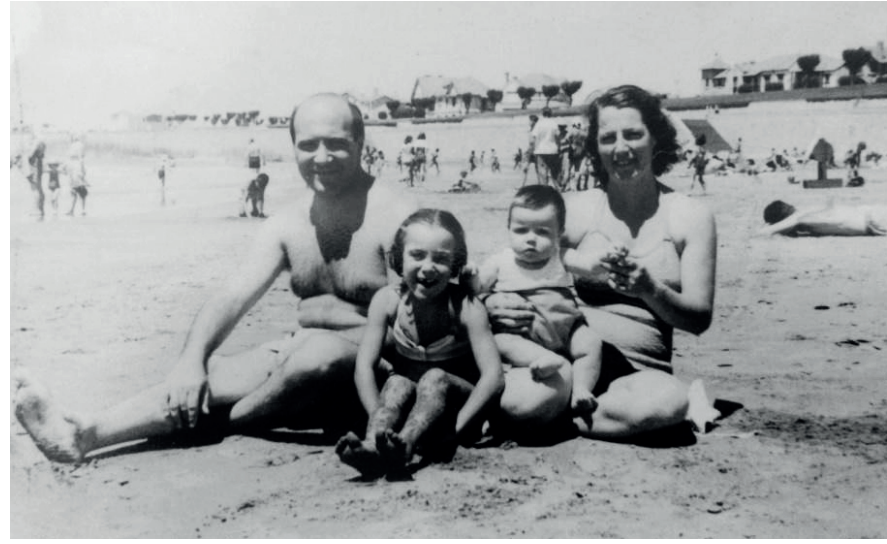

Pero además, este archivo posee cientos de fotografías no profesionales tomadas por sus mismos integrantes, que por lo menos desde la década del 40 dispusieron de una cámara fotográfica. Documentan otra clase de ritos: fundamentalmente, aquellos asociados al culto doméstico. Son las imágenes de los momentos intrascendentes de la vida cotidiana y junto con las otras, las que congelan los grandes acontecimientos, constituyen "objetos simbólicos dentro de la economía de sus relaciones privadas" ${ }^{20}$ Las amistades, en cambio, ocupan un lugar secundario al menos hasta la generación de Lucas, cuya sociabilidad masculina en la juventud es extensamente retratada en fotografías y documentada con una profusa correspondencia entre amigos. ${ }^{21}$

Imagen 4. Familia Rodríguez de vacaciones en Mar del Plata: Pedro Francisco, Aída Carmen, Aída Susana y María del Carmen. Archivo familiar Berman-Rodríguez, '1950.

La cercanía y la distancia en la vida cotidiana se vuelven claves para entender las formas en que se construye la afecreinventan a lo largo del tiempo. Quizás, la indagación en esta clase de archivos personales y familiares nos ayude a comprender las valoraciones sociales de las formas del sentir en cada período histórico.

Las instancias formales que documentan las relaciones de pareja (actas de matrimonio o de divorcio) pueden pensarse como contratos administrativos que las personas guardaron para ratificar (o negar) el parentesco ante distintas instancias estatales. Pero nada en el orden de la necesidad lleva a las personas a conservar invitaciones a las bodas de familiares y amigos cercanos, ni a guardar las fotos que congelan eventos sociales como casamientos y aniversarios. Y sin embargo, se conservan. Nacimientos, bodas y cumpleaños forman parte de los ritos sociales asociados a los ciclos de la vida y los archivos personales (éste en particular) tienden a inscribirlos en el relato del linaje. Las fotografías y los álbumes de imágenes familiares tienen la función de solemnizar y eternizar los grandes momentos de la vida en familia, de manera que refuerzan la integración del grupo (Imagen 4).19

18 Peter y Carol Stearns se interrogaron por las reglas que gobiernan la expresión de las emociones en sociedad o en subgrupos sociales en cada período histórico en su trabajo "Emotionology: Clarifying the History of Emotions and Emotional Standards", en The American Historical Review, vol. 90, $n^{\circ} 4,1985$. Sobre las transformaciones en el amor romántico y el "mercado matrimonial", Eva Illouz, Por qué duele el amor: una explicación sociológica, Buenos Aires, Capital Intelectual, 2012.

19 Pierre Bourdieu, Un arte medio. Ensayos sobre usos sociales de la fotografía, Barcelona, Gustavo Gili, 2003 [1965]. tividad. Las cartas de Susana a sus suegros, al mes y medio de nacido Lucas, agradeciendo sus regalos y poniéndolos al tanto del crecimiento del bebé, acercaron a sus abuelos (que vivían en Buenos Aires) al nieto nacido en Bariloche. Esas mismas líneas narran el enojo y la angustia de una madre primeriza y todavía puérpera que debía volver al trabajo docente con un bebé en brazos de 45 días, en medio de un conflicto gremial que extendió el ciclo lectivo sobre el mes de enero. ${ }^{22}$

Las cartas de Lucas cuando niño a su padre, que vivió primero en Bariloche y luego en Brasil, contando un sinfín de pequeños acontecimientos de su vida diaria, nos ponen frente al gesto de un niño, hijo de padres separados, que se esfuerza por tener al corriente a su padre de las vicisitudes de su vida. ${ }^{23}$ La letra in-

20 Luis Príamo, "Fotografía y vida privada", en Fernando Devoto y Marta Madero (comps.), Historia de la vida privada en la argentina, 18701930, vol. 2, Buenos Aires, Taurus, 1999, p. 276.

21 Dado que desarrollar esta cuestión ameritaría un trabajo aparte, queremos dejar constancia (aunque no nos ocupemos de ello en esta oportunidad) que nos sorprendió encontrar tantos registros de la práctica de escritura entre varones adolescentes. Ambas estábamos convencidas de que la correspondencia entre amigas era históricamente una práctica especialmente femenina. Este descubrimiento debería alentar trabajos que reflexionen acerca de la historia de la amistad y de las prácticas cotidianas sobre las que se estructuran esta clase de vínculos en ciertos momentos históricos.

22 Los documentos de esta época no dejan traslucir cómo era la organización en esa familia de tres. No sabemos quién cuidaba a Lucas mientras Susana daba clase, quizás la ocupación del padre (que intuimos flexible en cuanto a la organización de los horarios) le permitiese quedarse a cargo del bebé. Tampoco sabemos cómo estaban repartidas las tareas domésticas.

23 Es significativo que este archivo no contenga las cartas que Carlos le 
fantil, desplegada sobre hojas de cuaderno, contrasta con su conocimiento de ciertas reglas de la correspondencia, la forma de comunicación posible de un niño con su padre a la distancia en la década del 80, cuando las líneas telefónicas no funcionaban todavía muy aceitadamente. ${ }^{24}$ Pero los dibujos y cartitas dedicadas a mamá, expresando ese amor tan almibaradamente infantil, también nos acercan a las formas en que los niños construyeron sus vínculos afectivos viviendo con sus progenitores. Podemos pensar entonces en la correspondencia como soporte de los vínculos, como medio de construir una cotidianeidad con aquellos afectos que no están cerca. Las cartas con las primas, las cartas de las tías y hasta de los amigos (de viaje o vacacionando) nos permiten indagar en los términos en que esas relaciones se estructuraron a lo largo de la vida, en una época sin WhatsApp.

\section{(c) Una historia material de la felicidad infantil}

Otra línea posible de indagación, vinculada con lo anterior, es la que nos invita a pensar la cultura material de la infancia y la familia. ${ }^{25}$ Un objeto adquiere particular relevancia en este sentido: el álbum "Recuerdos felices de mi vida" que Aída Carmen dedicó al nacimiento de su hija Aída Susana, ocurrido el 3 de marzo 1945.

Impreso en serie y regalado a Aída Carmen próxima a tener a su primera hija, es parte de un género que existe hasta la actualidad —el de los álbumes pensados para que las madres anoten datos, recuerdos y anécdotas de los primeros años de vida de sus hijos e hijas-, pero que difícilmente hubiera existido en décadas anteriores. ${ }^{26}$ En otra investigación trabajamos la emergencia de una nueva sensibilidad por la infancia en los años $30 .{ }^{27}$ Esta implicaba

dirigía a su hijo Lucas.

24 Esa comunicación epistolar entre Lucas y su padre se mantendrá hasta el fallecimiento de Carlos en 2006

25 Como sostiene Calvert, el vínculo entre los artefactos materiales de infancia y la familia y las construcciones culturales a ellos asociada, hace que "el estudio de la cultura material sea un método importante para obtener acceso a las creencias y suposiciones culturales tan básicas que rara vez se verbalizan". Karin Calvert, "Children in the House. The material culture of early childhood", en Henry Jenkins, ed., The Children's culture reader, NY \& London, New York University Press, 1998, p. 68.

26 Según Artières, se trata de una práctica cuya función es inscribir al recién nacido en una normalidad y garantizarle una identidad. Artières, "Arquivar a própria vida", op. cit., p. 15

27 Nos referimos al siguiente trabajo: Ludmila Scheinkman, "Publicidades de golosinas, consumo y felicidad infantil (Argentina, 1930-1943)", en Anuario del Instituto de Historia Argentina, vol. 18, n 1, 2018. Sobre la infancia en los años 30 ver Isabella Cosse, Estigmas de nacimiento: peronismo y orden familiar, 1946-1955, Buenos Aires: Universidad San Andrés, FCE, 2006; sobre los niñxs consumidores ver Paula Bontempo, "Los niños de Billiken: las infancias en Buenos Aires en las primeras décadas de siglo XX", en Anuario del Centro de Estudios Históricos "Prof. Carlos S. A. Segreti", vol. 12, n 12, 2012, pp. 205-221 y "Enseñando a las niñas a consumir. La revista infantil Marilú (1933-1937)", en Avances del Cesor, vol. 12, n 13, 2015, pp. 107-132; Sandra Szir, Infancia y cultura visual: los periódicos ilustrados para niños (1880-1910), Buenos Aires, Miño y Dávila, 2007; "Imágenes para la infancia. Entre el la universalización de espacios específicos para niños y niñas. Extensamente retratados en los fondos de esta familia, aparecen la escuela pero también recreaciones como las vacaciones, el club, la escuela de danzas o la colonia, que surgen asimismo como algunos de los sitios en los que transcurría la infancia en estas décadas. Pero asimismo, esta noción universal de infancia se ligó a la idea de la felicidad como mandato imperativo que madres y padres debían cumplir para hacer felices a sus hijos e hijas y ser "buenos padres". Este mandato se ligó estrechamente a la dimensión del consumo y se pretendía universal, aunque no todas las familias pudieran sostener el nivel de gasto implícito en ella. En efecto, una de las formas de proveer infancias felices era a través de la adquisición de bienes que dieran alegría y placer a las y los pequeños.

El álbum "Recuerdos felices de mi vida" ya en su título lleva esta propuesta: los recuerdos felices son los recuerdos de infancia. Pero su contenido refuerza aún más la idea, ya que sus páginas contienen densas descripciones de regalos recibidos, juguetes y objetos varios (Imagen 5). Junto al registro del peso y la estatura, las primeras palabras, el primer diente, la primera comida o los primeros pasos, el álbum incluía páginas para apuntar los "regalitos" recibidos en el nacimiento del bebé. Estos fueron registrados con gran celo por Aída Carmen, indicando quién había obsequiado cada cosa, desde ropa y cochecitos hasta una libreta de ahorros para la pequeña. Además permitía asentar con fotos un evento como el bautismo y habilitaba el espacio para anotar los regalos recibidos en la fecha, y una página específica incluía los "primeros juguetes". Los regalos de Reyes Magos y Navidad, que incluían pequeños objetos de limpieza, dinero y muñecas, dialogan con las fotos de la fiesta del primer cumpleaños, o los entretenimientos de la niña, como un triciclo y juguetes varios. Estas extensas descripciones de asistentes a eventos y sus regalos nos hablan de una sociabilidad familiar pero también de una cultura del juguete, el regalo y los objetos materiales que hacen a la construcción y definición de la felicidad infantil afianzada en los años 40, donde felicidad y consumo parecían coagular y dar carne a la figura de la niñez consumidora y sus espacios de ocio y festejos familiares. Este álbum nos permite ligar, asimismo, la forma en que el discurso publicitario dirigido a la infancia empalmó con las prácticas cotidianas de las familias de clases medias, con poder adquisitivo suficiente para adquirir juguetes y objetos para la infancia. A partir de aquí, se abre un enorme campo de indagación que supone trabajar para entender cómo ciertos ob-

discurso pedagógico y la cultura del consumo en Argentina. La escuela y el periódico Ilustrado Caras y Caretas (1880-1910)", en Susana Sosenski y Elena Jackson Albarrán, eds., Nuevas miradas a la historia de la infancia en América Latina: entre prácticas y representaciones, México, Universidad Nacional Autónoma de México, Instituto de Investigaciones Históricas, 2012, pp. 123-152. Sobre la historia de los juguetes en nuestro país: Daniela Pelegrinelli, Diccionario de juguetes argentinos: infancia, industria y educación 1880-1965, Buenos Aires, El Juguete Ilustrado Editor, 2010 
jetos se invisten de significación para niñxs y adultxs. ${ }^{28}$

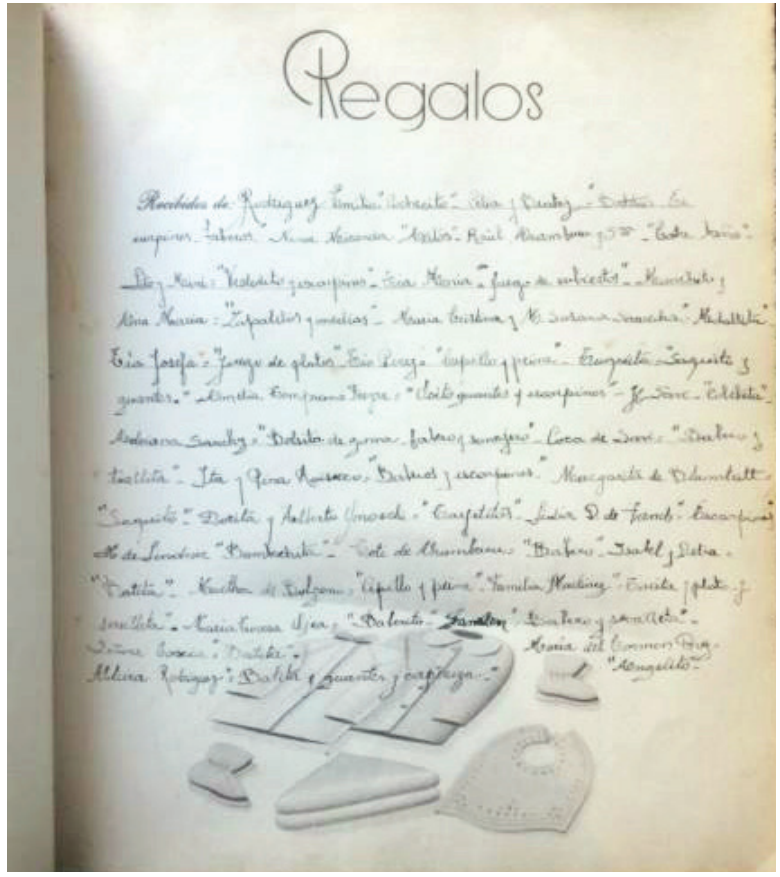

Imagen 5. Álbum "Recuerdos felices de mi vida". Archivo familiar

Berman-Rodríguez. Detalle de los regalos recibidos por el nacimiento de Aída Susana. 1945.

Como estas líneas sugieren, las posibilidades para inquirir en estos archivos son múltiples. El fondo incluye objetos y papeles de distintas épocas, de desigual densidad y procedencia, disímiles en su materialidad, que pueden ser interrogados desde inquietudes, puntos de vista y líneas de pesquisa variadas. Hemos tomado algunos objetos para cuestionarlos desde nuestras preguntas y campos de investigación particulares, pero sus ramificaciones exceden con mucho las mencionadas, e incluso las que nosotras, como investigadoras del tiempo presente, podamos llegar a imaginar. Con todo, pretendemos haber argumentado, cuanto menos, la necesidad de encarar seriamente su acopio y conservación, cuestión con la que quisiéramos cerrar estas páginas.

\section{Palabras finales}

En la actualidad existen en nuestro país pocas instituciones interesadas en preservar archivos personales de la "gente minúscula". Pero no es por falta de interés de lxs archivistas ni de las instituciones existentes. Los problemas derivados de la falta de políticas de conservación patrimonial en general hacen extensi-

28 Sharon Brookshaw, "The Material Culture of Children and Childhood. Understanding Childhood Objects in the Museum", en Journal of Material Culture, vol. $14, n^{\circ} 3,2009$, pp. 365-383. vas sus consecuencias a quienes estamos interesadxs en trabajar sobre archivos personales, una clase de archivos sobre los que la reflexión es reciente. ${ }^{29}$ Sin embargo, como hemos propuesto en estas páginas, su riqueza para la investigación histórica es notable, en al menos los tres campos que desarrollamos aquí: la historia de las clases medias, de las parejas, familias y afectividades, y la cultura material de las infancias. Sin embargo, sus potencialidades y ramificaciones exceden con mucho las abordadas.

Este trabajo fue posible por la sensibilidad de su propietario, que creyó que los papeles de su vida, y los de su familia, podían tener algún valor para quienes trabajamos con el pasado, valor que pretendemos haber argumentado en las páginas precedentes. No es menor, en este caso, el hecho de que Lucas Berman sea un arquitecto especializado en conservación patrimonial.

Es por eso, por la contingencia que supuso la conversión de estas cajas en archivo, que necesitamos crear espacios institucionales que rescaten las historias personales y familiares de la gente común. No sólo espacios que alberguen las posibles donaciones, que gestionen su clasificación y se comprometan con su preservación, sino que hagan un llamamiento a la comunidad explicando la importancia de contar con ellas para futuras investigaciones. Se trata de crear conciencia de su relevancia para el enriquecimiento del patrimonio colectivo. Ese trabajo arduo e invisibilizado de traccionar restos de la cultura material de las personas de carne y hueso para conformar archivos históricos requiere de la decisión de quienes dirigen la tarea de conformar el patrimonio de todxs nosotrxs, y de políticas públicas que estén a la altura del desafío.

\section{Referencias bibliográficas}

Adamovsky, Ezequiel, Historia de la clase media argentina: apogeo y decadencia de una ilusión, 1919-2003, Buenos Aires, Planeta, 2009.

Altamirano, Carlos, "La pequeña burguesía, una clase en el purgatorio", en Prismas, n¹, 1997, pp. 105-123.

Artières, Philippe, "Arquivar a própria vida", en Estudos Historicos, $n^{\circ} 21,1998$, pp. 9-34.

Artières, Philippe y Kalifa, Dominique "El historiador y los archivos personales: paso a paso", en Políticas de la Memoria, $n^{\circ} 13$, 2012/13, pp. 7-11.

29 Para una intensa reflexión en torno a los problemas que presentan los archivos personales, véase Horacio Tarcus, "Políticas de archivo desde la periferia", en María Virginia Castro \& María Eugenia Sik (comps.), Actas de las II Jornadas: Los archivos personales, op. cit., pp. 14-19. También Lila Caimari, La vida en el archivo, Buenos Aires, Siglo XXI, 2017. 
Bjerg, María, "Una genealogía de la historia de las emociones", en Quinto Sol, vol. 23, n 1, enero-abril, 2019.

Bontempo, Paula, "Los niños de Billiken: las infancias en Buenos Aires en las primeras décadas de siglo XX", en Anuario del Centro de Estudios Históricos "Prof. Carlos S. A. Segreti", vol. 12, $n^{\circ} 12,2012$, pp. 205-221.

Bontempo, Paula, "Enseñando a las niñas a consumir. La revista infantil Marilú (1933-1937)", en Avances del Cesor, vol. 12, n 13, 2015, pp. 107-132.

Bontempo, Paula; Bisso, Andrés, eds., Infancias y juventudes en el siglo XX, Buenos Aires, Teseo, 2018.

Bourdieu, Pierre, Un arte medio. Ensayos sobre usos sociales de la fotografía, Barcelona, Gustavo Gili, 2003 [1965].

Brookshaw, Sharon, "The Material Culture of Children and Childhood. Understanding Childhood Objects in the Museum", en Journal of Material Culture, vol. 14, n³ 3, 2009, pp. 365-383.

Caimari, Lila, La vida en el archivo, Buenos Aires, Siglo XXI, 2017.

Calvert, Karin, "Children in the House. The material culture of early childhood", en Henry Jenkins, ed., The Children's culture reader, NY \& London, New York University Press, 1998.

Carli, Sandra (ed.), La cuestión de la infancia: entre la escuela, la calle y el shopping, Buenos Aires: Paidós, 2006.

Cosse, Isabella [et. al.]., Infancias: políticas y saberes en la Argentina y Brasil : siglos XIX y XX, Buenos Aires, ANPCyT-UNGS, Teseo, 2011.

Cosse, Isabella, Estigmas de nacimiento: peronismo y orden familiar, 1946-1955, Buenos Aires: Universidad San Andrés, FCE, 2006.

Cosse, Isabella, Pareja, sexualidad y familia en los años sesenta. Una revolución discreta en Buenos Aires, Buenos Aires, Siglo XXI, 2010.

Cosse, Isabella, "Mafalda: Middle Class, Everyday Life and Politics in Buenos Aires, 1964-1973", en Hispanic American Historical Review, vol, 1, n 94, enero de 2014, pp. 35-75.

Cosse, Isabella, Mafalda: Historia social y política, Buenos Aires, Fondo de Cultura Económica, 2014.

Funes, Patricia "A veces enciendo la luz para no ver: memoria, archivo personal y espacio biográfico", en VIII Jornadas de Sociología de la UNLP, Ensenada, UNLP, 2014. Disponible en http:// www.memoria.fahce.unlp.edu.ar/trab_eventos/ev.4471/ev.4471. pdf
Illouz, Eva, Por qué duele el amor: una explicación sociológica, Buenos Aires, Capital Intelectual, 2012.

Lionetti, Lucía y Míguez, Daniel, Las infancias en la historia argentina: intersecciones entre prácticas, discursos e instituciones, 1890-1960, Rosario, Prohistoria, 2010.

Llobet, Valeria, ed., Pensar la infancia desde América Latina: un estado de la cuestión, Buenos Aires, CLACSO, 2014.

Manzano, Valeria "'Y, ahora, entre gente de clase media como uno...'.Culturas juveniles, drogas y política en la Argentina, 19601980 ", en Contemporánea. Historia y problemas del siglo $\mathbf{X X}$, $n^{\circ} 5,2014$, pp. 85-104

Pelegrinelli, Daniela, Diccionario de juguetes argentinos: infancia, industria y educación 1880-1965, Buenos Aires, El Juguete Ilustrado Editor, 2010.

Perec, Georges, Especies de espacios, Barcelona, Montesinos, 2001 [1974].

Philippe Artières, "S'archiver (Archivarse)" en María Virginia Castro y María Eugenia Sik, (comps.), Actas de las II Jornadas: Los archivos personales: prácticas archivísticas, problemas metodológicos y usos historiográficos, Buenos Aires, CeDlnCl, 2017, pp. 37-49.

Príamo, Luis, "Fotografía y vida privada", en Fernando Devoto y Marta Madero (comps.), Historia de la vida privada en la argentina, 1870-1930, vol. 2, Buenos Aires, Taurus, 1999.

Queirolo, Graciela, Mujeres en las oficinas. Trabajo, género y clase en el sector administrativo (Buenos Aires, 1910-1950), Buenos Aires, Biblos, 2018.

Scheinkman, Ludmila, "Publicidades de golosinas, consumo y felicidad infantil (Argentina, 1930-1943)", en Anuario del Instituto de Historia Argentina, vol. 18, $n^{\circ} 1,2018$. Disponible en https:// doi.org/10.24215/2314-257Xe068

Stearns, Peter y Stearns, Carol "Emotionology: Clarifying the History of Emotions and Emotional Standards", en The American Historical Review, vol. 90, n4, 1985, pp. 813-836.

Szir, Sandra, Infancia y cultura visual: los periódicos ilustrados para niños (1880-1910), Buenos Aires, Miño y Dávila, 2007.

Szir, Sandra, "Imágenes para la infancia. Entre el discurso pedagógico y la cultura del consumo en Argentina. La escuela y el periódico Ilustrado Caras y Caretas (1880-1910)", en Susana Sosenski y Elena Jackson Albarrán, eds., Nuevas miradas a la 
historia de la infancia en América Latina: entre prácticas y representaciones, México, Universidad Nacional Autónoma de México, Instituto de Investigaciones Históricas, 2012, pp. 123-152.

Tarcus, Horacio, "Políticas de archivo desde la periferia", n María Virginia Castro y María Eugenia Sik, (comps.), Actas de las II Jornadas: Los archivos personales: prácticas archivísticas, problemas metodológicos y usos historiográficos, Buenos Aires, CeDInCl, 2017, pp. 14-19.

Villalta, Carla, Infancia, justicia y derechos humanos, Bernal, Universidad Nacional de Quilmes, 2010; Visacovsky, Sergio y Garguin, Enrique, Moralidades, economías e identidades de clase media, Buenos Aires, Antropofagia, 2009.

\section{Resumen}

El objetivo de este trabajo es una primera aproximación al archivo personal de la familia Berman-Rodríguez [ca. 1897-2010], una familia de clase media porteña, para reflexionar sobre los límites, potencialidades y vías que abre la exploración de fondos de "gente común". De las muchas aristas posibles, nos interesa profundizar en tres, como una forma de argumentar acerca de sus potencialidades para la investigación histórica, y la necesidad de su conservación: la historia de las clases medias y del ascenso social, la historia de las infancias y familias -en consonancia con los estudios históricos de la afectividad- y una historia material de la felicidad infantil. Esperamos que esta reflexión sobre los archivos personales de personajes y familias anónimas sea una ocasión para pensar posibles líneas de indagación, y un alegato en torno a la necesidad de incentivar el acopio y la conservación de los archivos familiares en instituciones especializadas.

Palabras clave: archivos familiares; familias; infancias; clases medias

\section{Abstract:}

The Berman-Rodriguez Family: Exploring the Problems, Limits and Potentialities of a Personal/Family File

The purpose of this paper is to preliminary approach the personal archive of the Berman-Rodríguez family [ca. 1897-2010], of middle-class background, to reflect on the limits, potentialities and possibilities that are opened by the exploration of archival holdings of "common people". From the many possibilities that arouse, we are interested in exploring three, as a means of arguing about their potential for historical research, and the need for their conservation: the history of middle classes and social ascension, the history of childhoods and families - in line with historical studies of affection - and a material history of childhood happiness. We hope that this reflection about the personal files of anonymous people and families will be an occasion to think about the possible lines of inquiry, and an allegation on the need to encourage the support and conservation of family archives in specialized institutions.

Keywords: family archives; families; childhoods; middle classes.

Recibido el 31/06/2019

Aceptado el 25/09/2019 


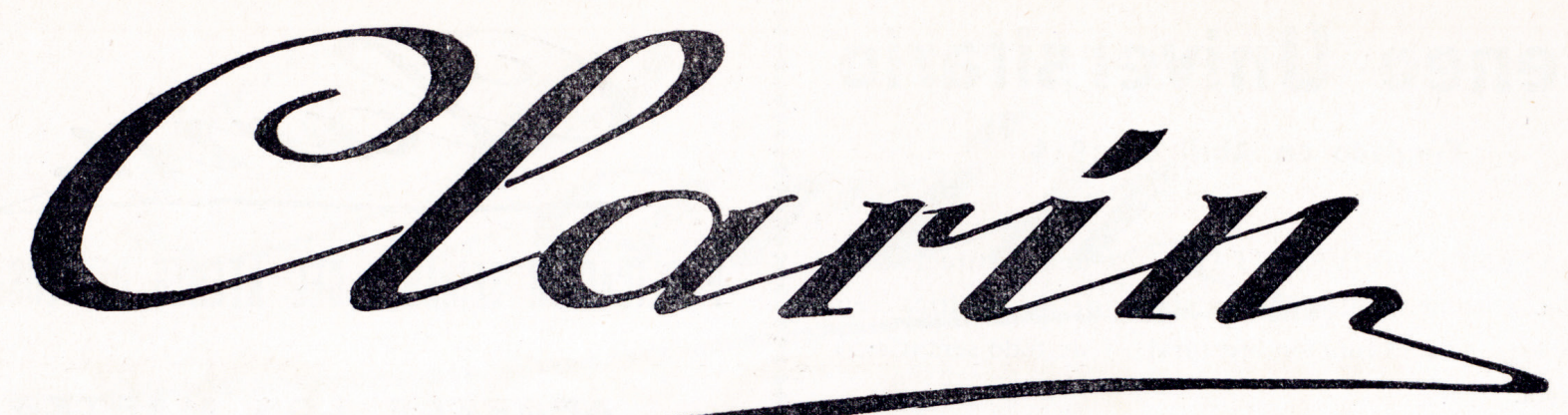

Precio del ejemplar $\$ 0.10$

Buenos Aires, febrero 17 de 1920

Año I - N ${ }^{\circ} 17$

De la familia periodística

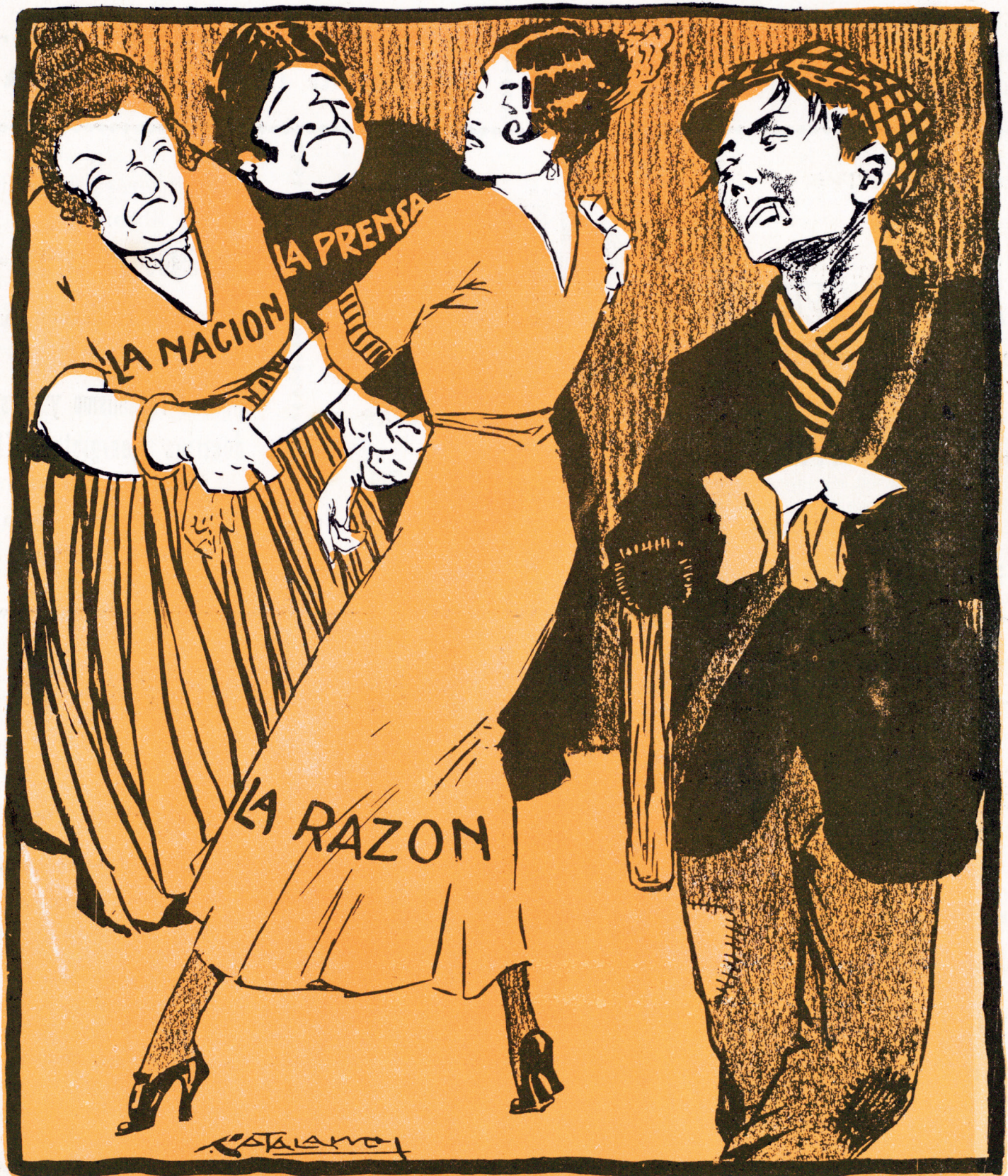

El canillita: - Fácil es comprender, el "interés" que tienen las viejas en defender el "honor" de la muchacha. 